\title{
Nanoscale Mechanics of Ductile Interphases in Oxide Composites
}

\author{
Nasim Alem*, Vinayak P Dravid *\# \\ * Department of Materials Science and Engineering, Northwestern University, 2220 Campus Dr., \\ Evanston, IL, 60208 \\ \# International Institute for Nanotechnology, Northwestern University, 2220 Campus Dr., Evanston, \\ IL, 60208
}

Interfaces play a significant role on deformation and fracture behavior of structural materials, especially composites. Large scale mechanical properties of interface-controlled materials are strongly influenced by all attributes of interfaces, such as atomic structure, chemistry and bonding as well as residual stresses, size scale and plasticity of the phases. Among several ways to enhance mechanical behavior of composites, we have chosen to study the effect of nanoscale ductile interphases on the fracture and deformation behavior of composite materials. The objective of this work is to present the role of ductile interphases on the deformation and fracture behavior of interface-controlled materials and to understand the correlative mechanisms operating in these systems at various length scales.

We have chosen $\mathrm{Ni}_{\mathrm{x}} \mathrm{Co}_{1-\mathrm{x}} \mathrm{O} / \mathrm{ZrO}_{2}$ Directionally Solidified Eutectics (DSEs) as a model system in this work, since formation of $\mathrm{Ni}(\mathrm{Co})$ ductile interphases is readily feasible upon reduction of this composite at high temperatures [1-2]. Formation of nanoscale $\mathrm{Ni}(\mathrm{Co})$ ductile interphases occurs due to the formation of an electrochemical cell within the $\mathrm{Ni}_{\mathrm{x}} \mathrm{Co}_{1-\mathrm{x}} \mathrm{O} / \mathrm{ZrO}_{2}$ DSEs at high temperatures [12]. The electrochemical behavior in this system owes itself to the high oxygen ion conductivity of $\mathrm{ZrO}_{2}$ phase and high electrical conductivity of $\mathrm{Ni}(\mathrm{Co})$ metallic layer.

Addition of the transition metal interphase $(\sim 100 \mathrm{~nm})$ shows significant improvements in the fracture and deformation behavior of the reduced $\mathrm{Ni}_{\mathrm{x}} \mathrm{Co}_{1-\mathrm{x}} \mathrm{O} / \mathrm{ZrO}_{2}$ compared to the pristine system [3]. This improvement is due to the presence of thin ductile interphases, which can enhance the strain energy absorption through elimination of sharp cracks, formation of secondary cracks and interfacial crack delamination upon loading. Figure 1 shows the fracture and deformation behavior of $\mathrm{Ni}_{0.5} \mathrm{Co}_{0.5} \mathrm{O} / \mathrm{ZrO}_{2}$ composites before and after formation of the $\mathrm{Ni}(\mathrm{Co})$ ductile interphases. Figure 2 shows the microstructure and the interfacial chemistry of the reduced $\mathrm{CoO} / \mathrm{ZrO}_{2}$ composites moving from metallic Co to $\mathrm{ZrO}_{2}$. The black line across the Co- $\mathrm{ZrO}_{2}$ interface in Figure 2a shows the particular area of analysis in this sample. According to Figure 2 the chemical changes take place within a thickness of 2-3 nm across the interface. Figure $2 b$ and $2 \mathrm{c}$ indicate depletion of oxygen from the interphase and rise of the $\mathrm{Ca}$ and $\mathrm{Zr}$ edges as we enter $\mathrm{ZrO}_{2}$ phase.

Scanning and transmission electron microscopy techniques are utilized to investigate the role of ductile interphases in this study. Multitude of electron microscopy techniques, including localized EDS and EELS, are employed to uncover the interfacial microstructure and chemistry in the composite upon reduction. This work also aims to reveal and correlate deformation and fracture behavior in the reduced $\mathrm{Ni}_{\mathrm{x}} \mathrm{Co}_{1-\mathrm{x}} \mathrm{O} / \mathrm{ZrO}_{2}(\mathrm{CaO})$ model system at various length scales [4]. 
References:

[1] B. Bonvalot-Dubois, G. Dhalenne, J. Berthon, et al., J. Am. Ceram. Soc., 71 [4] (1988) 296

[2] B. Bonvalot-Dubois, G. Dhalenne, A. Revcolevschi, Mat. Res. Soc. Proc., 138 (1989) 587

[3] N. Alem, V. P. Dravid, J. Am. Ceram. Soc., 89 [2] (2006) 767

[4] This research is partially supported by DOE-BES. The electron microscopy work in this research was performed in the EPIC facility of the NUANCE Center at Northwestern University. NUANCE

Center is supported by NSF-NSEC, NSF-MRSEC, Keck Foundation, the State of Illinois, and Northwestern University.
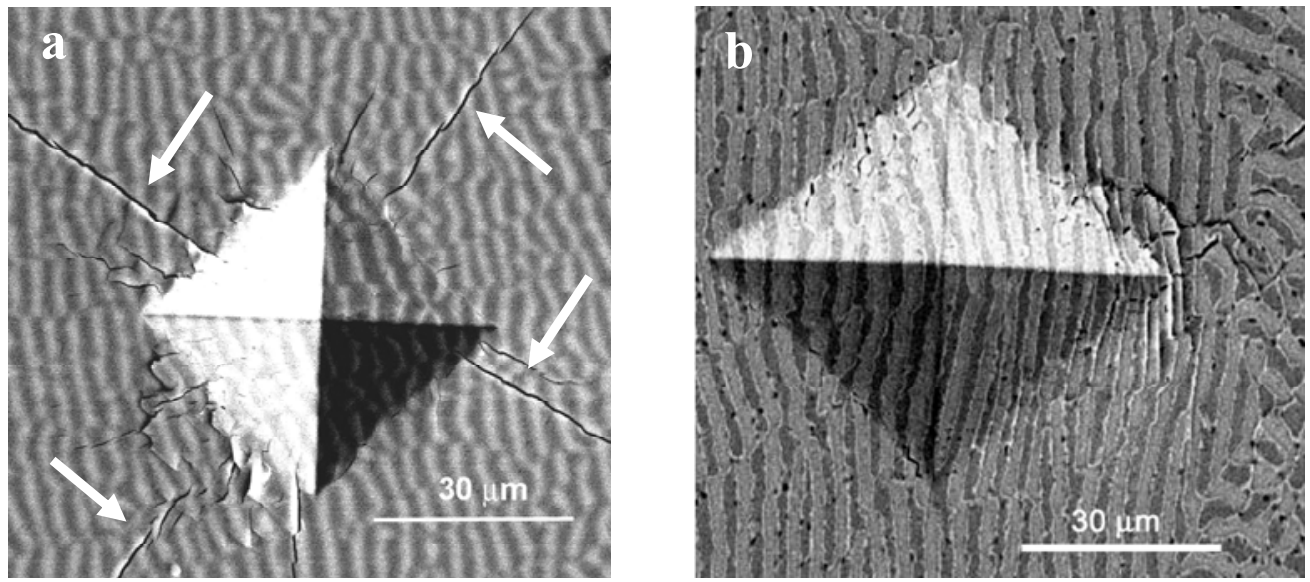

Figure 1. Deformation and fracture behavior of $\mathrm{Ni}_{0.5} \mathrm{Co}_{0.5} \mathrm{O} / \mathrm{ZrO}_{2}$ DSE composite upon Vickers indentation test (a) before and (b) after reduction. (a) Notice the sharp cracks indicating brittle fracture mechanism in the pristine composite. (b) The reduced composite shows enhanced energy dissipative mechanisms, leading to interfacial delamination, crack arrest and crack bridging across the ductile interphase.

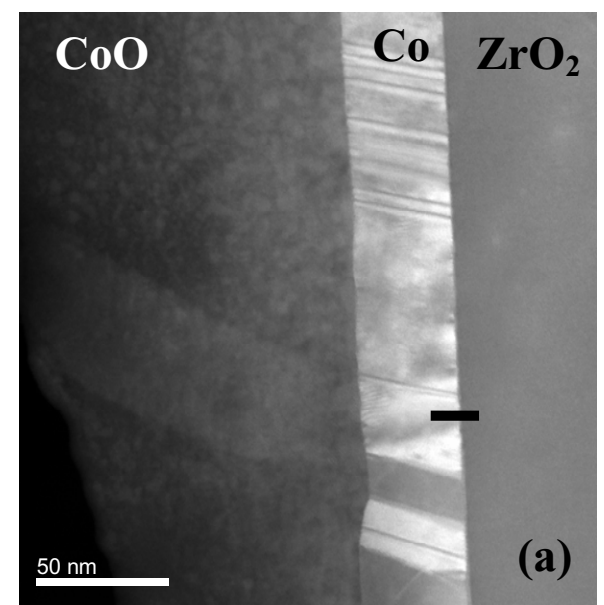

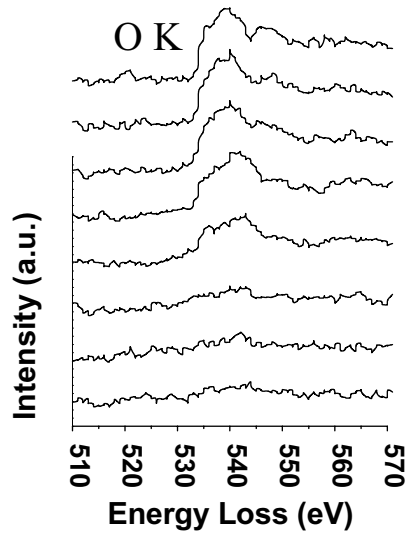

(b)

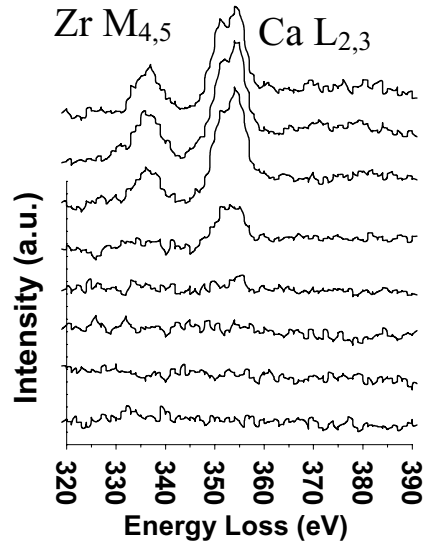

(c)

Figure 2. (a) Dark field STEM image of the reduced $\mathrm{CoO} / \mathrm{ZrO}_{2}$ with Co interphase mediating the oxide phases. (b,c) Electron Energy Loss Spectroscopy (EELS) across the Co- $\mathrm{ZrO}_{2}$ interface, showing depletion of oxygen moving from the Co interphase towards $\mathrm{ZrO}_{2}$. (Step size=0.65 nm) 